\title{
EL TERREMOTO DE LISBOA EN LAS CARTAS DEL KURIER POLSKI O CORREO POLACO
}

\author{
Matylda Urjasz-Raczko* \\ Universidad de Varsovia
}

\section{El desarrollo de la prensa en la Rzeczpospolita Obojga Narodów hasta 1729}

Hasta 1729 no había en la Rzeczpospolita Obojga Narodów' ninguna revista de estilo occidental y tampoco se seguían las pautas del periodismo marcadas por Inglaterra y los Países Bajos. A pesar del régimen constitucional, las revistas no existían como foro en el que presentar polémicas políticas ni otros debates. El único ensayo que había tenido lugar hasta entonces duró sólo un año. Fue una iniciativa del monarca Juan Casimiro, quien en 1661 ordenó editar una revista semanal Ilamada Merkuriusz Polski ("El Mercurio Polaco"), para divulgar sus ideas y sus planes reformistas. Junto con este primer intento editorial se publicaron también avisos y relatos ocasionales, así como algunos ensayos de reimpresión de la prensa alemana: Avvisi, Wiadomości cudzoziemskie ("Noticias extranjeras"), que pronto desaparecieron².

En 1718 Jan Dawid Cenkier imprimió Poczta Królewiecka ("El Correo de Krolewiec $\left.{ }^{\prime \prime 3}\right)$ para la colonia polaca en Prusia. Cenkier pensaba que estos polacos deseaban tener información sobre la Corte y el gobierno de Varsovia, pero la empresa quebró después de 29 meses debido a la falta de lectores ${ }^{4}$.

* Licenciada en Historia. Universidad de Varsovia.

1. "Comunidad de las Dos Naciones" -nombre del Estado resultante de la Unión de Lublin de 1569 entre el Reino de Polonia (la Korona) y el Gran Ducado de Lituania. Con diversas vicisitudes, la Comunidad (Rzeczpospolita) polaco-lituana perduró hasta la Tercera Partición de 1795. Véase J. Kieniewicz, Historia de Polonia, México, 2001, pp. 39-92.

2. J.A. Drob, Obieg informacji w Europie w połowie XVII wieku (La circulación de las noticias en la Europa de mediados del siglo XVII), Lublin, 1993, pp. 13-28; J. Łojek, Prasa Polska 1661-1864, (La prensa polaca 1661-1864), Varsovia, 1976, pp. 15-16.

3. Nombre polaco de Königsberg.

4. J. Łojek, Prasa Polska 1661-1864..., pp. 17-18. 
Los canales informativos y los lectores en la Rzeczpospolita Obojga Narodów del siglo XVIII

Cuando en Europa occidental la prensa alcanzó su pleno desarrollo, en la Rzeczpospolita comenzaron a notarse sus inicios. En el Estado polaco, donde el rey y la nobleza (szlachta ${ }^{5}$ y magnates ${ }^{6}$ ) constituían los únicos poderes políticos, y donde la burguesía carecía de la capacidad de influir en las leyes aprobadas por la Dieta (Sejm), cada clase social vivía en una realidad diferente y se abastecía por sí misma de la información demandada. Las revistas eran un artículo poco solicitado, como muestran los casos mencionados.

Un grupo tan reducido de lectores como era el constituido por los magnates y los nobles conseguía información por sus propios medios. Existían cuatro maneras básicas de obtener noticias, que a lo largo de los siglos habían sido elaboradas y adaptadas al estilo de vida de un magnate. La Dieta, las "dietinas" y las fiestas privadas eran una ocasión para reunirse e intercambiar novedades y cotilleos. Aparte de esto, algunos establecían alianzas secretas o se entrevistaban con sus informantes o espías; pero, en general, eran corrientes los encuentros de varios tipos como manera habitual de conseguir e intercambiar información y de usarla en beneficio propio o común?

Otra fuente de averiguación fue la lectura de revistas extranjeras recibidas por correo. Pero el modo más extendido de conseguir información, reservado al círculo privado de cada uno, fue la correspondencia. Las cartas privadas escritas entre la nobleza del territorio de la Rzeczpospolita y el resto del mundo fueron una fuente confidencial, escrita sin ninguna censura, y cuyo conteni-

5. La nobleza (szlachta) era en la Rzeczpospolita un grupo más numeroso que en otros países europeos; constituía alrededor del 10\% de la población (dependiendo de la región). Tenían derechos políticos, un poder decisivo en el país y bastantes privilegios económicos y políticos (generales o individuales). Gobernaban mediante representantes elegidos en las "dietinas" (sejmiki) o consejos regionales, que mandaban a la Dieta. Su riqueza se basaba en la propiedad rural. La pertenencia a esta clase era hereditaria, independiente de la fortuna; aunque excepcionalmente el título podía ser conferido por el rey o por decisión de la Dieta. Según la ley todos los miembros de esta clase eran iguales, pero sus propiedades variaban en una amplia escala de riqueza que iba desde la posesión de una sola aldea (o de ninguna), hasta fortunas que llegaban a los $15.000 \mathrm{~km}^{2}$.

6. Los magnates (magnateria, magnaci) eran los miembros más ricos de la szlachta o nobleza. Según el régimen constitucional de la Rzeczpospolita tenían los mismos derechos y privilegios que el resto de la nobleza; pero, en la práctica, su riqueza les otorgaba un poder considerable. Los miembros de este grupo ocupaban los puestos del senado y los cargos más elevados de la administración. Con su poder y riqueza influían en sus clientes, miembros inferiores de la nobleza, que se veían forzados a votar según los intereses del magnate correspondiente. Aunque este grupo no impulsaba ninguna política común, sino que cada uno se centraba en sus propios intereses, el siglo XVIII se considera la época de mayor influencia de los magnates en el gobierno del país mediante sus redes clientelares.

7. J. Łojek, Gazeta warszawska Księdza Łuskiny 1774-1793, (La revista varsoviana del Fraile Łuskina 1774-1793), Varsovia, 1759, pp. 8-10. 
do respondía al gusto particular de cada magnate: informaciones, noticias sensacionales, cotilleos y escándalos ${ }^{8}$.

El procedimiento más extendido en Francia, y conocido también en la Rzeczpospolita, era la revista. Un modo de conseguir información, reservado al reducido grupo de los poderosos, fue el encomendar la elaboración de una revista privada, forma extendida a lo largo de los siglos XVI y XVII. Un magnate que viviera fuera de la capital; es decir, del centro de las noticias, mantenía su propio corresponsal privado en Varsovia, quien estaba al tanto de todas las novedades y las refería en cartas a su protector. A menudo, estos grupos de periodistas confidenciales-espías incluían a varios lectores y copistas constituyendo en la práctica una verdadera empresa comercial ${ }^{9}$.

La competencia con las revistas importadas del extranjero y las privadas, así como el sistema de monopolios, hacía difícil establecer una prensa nacional que fuera regular.

\section{La prensa regular a principios del siglo XVIII}

Después de la derrota sufrida frente a Suecia en la Gran Guerra del Norte (1700-1715), se hizo necesario impulsar la revitalización de la capital, la cual se produjo con mayor rapidez que la de otros núcleos urbanos y económicos. Varsovia se convirtió en el centro político, administrativo y cultural de la Rzeczpospolita; además, se estableció en ella la residencia permanente del rey con su Corte, y los grandes magnates disponían allí al menos de residencias. En torno a la Corte del rey y a las de los magnates existía un numeroso grupo de nobles que ofrecían sus servicios, hidalgos pobres que eran clientes de aquellos. Esta concentración de cortes (de los magnates y del rey) animó el comercio y la artesanía en la ciudad, sobre todo en cuanto a artículos de lujo. Además de ser Varsovia un foco de bienes económicos, era el centro de la intelectualidad del país. En la Dieta, las cortes y las escuelas de Varsovia se tomaban decisiones políticas y se discutía sobre las reformas que era necesario emprender, entre ellas las referentes a la educación y la prensa ${ }^{10}$.

En un lugar así podía surgir la demanda de prensa y bastantes clientes que se suscribieran a ella. Aunque la prensa la compraban los magnates y algunos nobles en todo el territorio de la Rzeczpospolita Obojga Narodów, sus princi-

8. W. Jurkiewicz, "Korespondencja elit stanisławowskich", ("La correspondencia de la elite en la época estanislava), Rozprawy z dziejów XVIII wieku. Z dziejów komunikacji socjalnej epoki nowożytnej, (Debates sobre el siglo XVIII. La historia de la comunicación social en la época moderna), red. J. Wojtowicz, Toruń, 1993, pp. 33-44.

9. J. A. Drob, Obieg informacji w Europie w XVII wieku..., pp. 59-60; J. Łojek, Prasa polska 1661-1864..., p. 29; Gazeta warszawska..., pp. 12-15.

10. J. A. Drob, Obieg informacji w Europie w XVII wieku..., pp. 64-65. 
pales destinatarios, a lo largo del siglo XVIII, estaban en Varsovia y Vilna: sobre todo la Corte, los magnates y la burguesía acomodada.

Con esta perspectiva debemos contemplar el establecimiento de la primera revista en la ciudad de Varsovia, que durante el siglo XVIII será el mayor centro editorial y de consumo de la prensa.

La causa directa del establecimiento de la prensa regular en Varsovia surgió de la competencia entre jesuitas y escolapios ${ }^{11}$. Aunque estos últimos tenían fama de ser más progresistas, por incluir en su enseñanza las lenguas vivas y las ciencias naturales, eran los jesuitas quienes dominaban en el campo de la educación. El sistema de monopolios en la prensa funcionaba en toda Europa (Reino Unido, Holanda y algunos estados alemanes), como consecuencia de ellos se restringía la competencia y el desarrollo de la misma. La orden de los escolapios obtuvo la concesión del rey Augusto II (1609-1706 y 1709-1733) cum iure exclusivo, lo que significaba que ellos eran los únicos con derecho a editar una revista en Varsovia ${ }^{12}$.

\section{Breve historia del Kurier Polski}

El período de los escolapios: establecimiento del estilo de la revista

Durante las primeras décadas del siglo XVIII el Reino de Polonia se vio arruinado y saqueado debido a las sucesivas guerras con suecos, rusos y turcos. La pobreza aumentó entre los miembros de la burguesía y del campesinado y el país pasó progresivamente a depender en muchos aspectos de los zares rusos. Todos clamaban por una reforma del Estado ${ }^{13}$. Entre los nuevos proyectos surgió en 1729 la decisión de los escolapios de contratar a Jan Naumański, un historiador y geógrafo, como redactor de la revista. Las noticias salían una vez a la semana bajo una doble portada: la primera de las dos hojas que componían la revista se titulaba Nowiny Polskie ("Noticias polacas"), y la otra llevaba el título latino de Relata refero. Después de unos meses, el 21 de diciembre de 1729, estos títulos se cambiaron por los de Kurier Polski ("El Correo Polaco") y Uprzywilejowane wiadomości z cudzych krajów ("Novedades privilegiadas del extranjero"), respectivamente ${ }^{14}$.

11. Miembros de la Orden de los clérigos regulares pobres de la Madre de Dios de las Escuelas Pías (Ordo Clericorum Regularium Pauperum Matris Dei Scholarum Piarum), Ilamados también "piaristas" en los países germanos, eslavos y anglosajones, y "calasancios" en algunos países iberoamericanos. Fundados en Roma por San José de Calasanz a finales del siglo XVI, y aprobados como congregación religiosa por Pablo $\vee$ en 1617, fueron elevados por el papa Gregorio XV a la condición de Orden de votos solemnes en 1621. En Polonia se dedicaron desde 1642 a la educación primaria.

12. J. Łojek, Prasa polska w latach 1661-1864..., pp. 20-21.

13. J. Kieniewicz, Historia de Polonia ..., p. 77

14. J. Łojek, Dziennikarze i prasa w Warszawie XVIII wieku (Los periodistas y la prensa en Varsovia del siglo XVIII), Varsovia, 1960, pp. 20-34. 
Según los historiadores de la prensa, esta división entre noticias nacionales y extranjeras fue un fenómeno nuevo en el marco europeo. En los diarios de otros países europeos, de Londres a San Petersburgo, el 90\% de las noticias se referían al extranjero, mientras que, en este caso, el Kurier Polski presentaba las noticias de Polonia (la Korona) y Lituania, y la otra parte del mismo impreso, Uprzywilejowane wiadomości..., las de países foráneos ${ }^{15}$.

\section{Modos de obtener las informaciones}

El Kurier Polski, como la mayoría de las publicaciones periódicas europeas, no mantenía corresponsales permanentes en las principales ciudades para la circulación de las noticias, ya que era demasiado caro. Se abastecía de noticias mediante cartas escritas desde un gran número de ciudades y villas señoriales de la Rzeczpospolita. Todavía no está claro si Jan Naumański conseguía las noticias para su revista manteniendo una correspondencia continua con los escolapios de la República o si la gente le escribía por propia iniciativa informando de un hecho importante (una boda o un funeral en una familia de la nobleza, acuerdos de las "dietinas", o raros fenómenos de la naturaleza). En cualquier caso, las noticias de las principales ciudades de la Rzeczpospolita llegaban regularmente por correo dos veces a la semana. El redactor conseguía las novedades locales hablando directamente con la gente durante las sesiones de la Dieta, pero las informaciones locales no despertaban tanto interés y ocupaban poco espacio en las páginas de la revista ${ }^{16}$. La mayor parte de las noticias extranjeras procedían de varios títulos de la prensa extranjera suscritos por la redacción del Kurier Polski y todas las noticias se traducían al polaco para su publicación. Sólo algunas de ellas se obtenían de cartas privadas o de viajeros que llegaban a la capital. La revista desarrolló sus modos de conseguir las noticias, redactarlas y, sobre todo, de hacerse con un grupo bastante numeroso de lectores, Ilegando en el año 1736 a una tirada aproximada de 1.000 ejemplares ${ }^{17}$.

\section{El período de los jesuitas}

Los escolapios, con el redactor Jan Naumański al frente, editaron la revista hasta el año 1736, cuando perdieron el monopolio por un lapso editorial y las murmuraciones de los jesuitas. Al parecer (según las memorias de Antoni Magier), en la noticia referente al parto de la reina María Josefa (1719-1757), en vez de escribir królowa ("la reina"), se imprimió por error krowa ("la vaca"). En los ejemplares conocidos hoy en día no aparece esta errata, pero es posible que, después de advertida, la Corte confiscara toda la tirada original ${ }^{18}$.

15. J. Łojek, Prasa polska w latach 1661-1864..., p. 22.

16. J.A. Drob, Obieg informacji w Europie w XVII wieku..., pp. 56-64.

17. J. Łojek, Prasa polska w latach 1661-1864..., p. 23.

18. J. Łojek, Prasa polska 1661-1864..., pp. 23-24. 
Mayor importancia presenta el hecho de que, después de esto, los jesuitas consiguiesen el derecho de edición cum iure exclusivo y el control del Kurier Polski. A partir de enero de 1737, el Kurier Polski y las Uprzywilejowane wiadomości... fueron editados por los jesuitas ${ }^{19}$. A pesar de que los nuevos propietarios continúan con los mismos métodos editoriales, manteniendo el mismo título y la división en dos partes, la calidad de la impresión y el diseño gráfico disminuyó. El puesto de redactor jefe lo ocupa un desconocido Michał Łowisz hasta 1760. Al mismo tiempo, la revista pierde su clara división entre la parte de noticias nacionales e internacionales. Las Uprzywilejowane wiadomości... siguen presentando noticias extranjeras (en su mayor parte copiadas) pero en el Kurier Polski se empieza a insertar no sólo noticias locales y nacionales, sino también extranjeras.

En el año 1760 la redacción del Kurier la ocupa un famoso dramaturgo, el jesuita Franciszek Bohomolec, que reorganiza la redacción. A partir de enero de 1761 se imprimen dos revistas semanales: el Kurier Warszawski ("El Correo Varsoviano"), que salía los sábados, y las Wiadomości Warszawskie ("Novedades Varsovianas") los miércoles. Finalmente, en 1765 las Wiadomosci Warszawskie absorben al Kurier y el noticiero sale dos veces a la semana bajo el título de Wiadomości Warszawskie.

Un hecho significativo fue la abolición de la Compañía de Jesús en $1773^{20}$. La principal revista de la Rzeczpospolita, el Kurier Warszawski, cambió de propietario. Un colaborador de Franciszek Bohomolec, el padre Stefan Łuskina, obtuvo personalmente el privilegio vitalicio de editar noticieros en el Reino de Polonia en cualquier idioma menos en francés. La revista cambia otra vez de título, tomando el de Gazeta Warszawska ("Gaceta Varsoviana"), y se convierte prácticamente en el órgano político de los jesuitas y del rey Estanislao Augusto Poniatowski en todo el territorio del reino ${ }^{21}$.

Después de perder la propiedad de la revista, los escolapios no intentaron crear otra nueva hasta el año 1757, cuando consiguieron un nuevo privilegio real y fundaron una revista que se publicó en alemán, Warschauer Zeitungen, y en 1758 un diario en francés, la Gazette de Varsovie. La primera iba dirigida a la Corte y a la administración del rey Augusto III de Sajonia, así como a la burguesía de las ciudades de Toruń y Gdansk. La otra se creó para los que hablaban francés, el idioma de la llustración y sinónimo de la cultura.

En 1764 fue elegido para ocupar el trono de Polonia Estanislao Augusto Poniatowski, favorito de la zarina Catalina II. El rey se propuso sacar al país del retraso cultural y económico en el que se encontraba, pero aceptó un régimen de protectorado de Rusia convertido pronto en un intento de dominación. A

19. J. Łojek, Dziennikarze i prasa w Warszawie ..., p. 35.

20. Vease J. Kieniewicz, Historia de Polonia..., pp. 84-85.

21. J. Łojek, Gazeta warszawska..., pp. 20-21. 
partir de los años 60, la prensa experimenta un desarrollo en la Rzeczpospolita. Empiezan a aparecer revistas en Vilna y una en Varsovia, que ofrecen un perfil no sólo informativo sino también literario y científico ${ }^{22}$.

Las potencias vecinas encontraron pretextos suficientes para en 1772 organizar un primer reparto de las tierras de la Rzeczpospolita. Prusia se anexionó 36.000 km² del noroeste de Polonia, Rusia 92.000 del este y Austria 83.000 del sur. Polonia perdió un tercio de sus territorios y de su población. El Estado polaco inició un período de reformas, con un relativo florecimiento económico y cultural, hasta que en 1788, tras numerosas agitaciones políticas, tuvo lugar la Ilamada "Dieta de los Cuatro Años" o "Gran Dieta" (Sejm Wielki), que dictaba una serie de decretos en los que se rechazaba el protectorado de Rusia. Hasta entonces, la Gazeta Warszawska había sido la principal revista y casi la única, pero en ese período de la Sejm Wielki (1788-1792) se produce un boom de revistas que competían entre sí (cinco títulos sólo en Varsovia). Es entonces cuando va cambiando el objetivo de la prensa, convirtiéndose en un foro de facciones políticas e ideologías. En 1791 se aprueba la Constitución del 3 de mayo, en la que mediante el compromiso entre el rey y los dirigentes del Partido Patriótico, se abolió el liberum veto ${ }^{23}$ y el sistema de la monarquía electiva, estableciéndose una monarquía hereditaria, la delimitación del campo de influencias de la aristocracia, la extensión de derechos a la burguesía y el amparo de siervos y campesinos por parte de las leyes y del gobierno. Este período de desarrollo de la prensa y de la reforma del régimen de la Rzeczpospolita duró poco; terminó con la Confederación de Targowica ${ }^{24}$ y la intervención rusa, que para la prensa supuso la liquidación de los periódicos en el Estado polaco-lituano. ${ }^{25}$

Catalina II no aceptó tales medidas de reforma y en el año 1792 el ejército ruso, apoyado por parte de la aristocracia conservadora polaca, invadió Polonia,

22. J. Łojek, Prasa polska 1661-1864 ..., pp. 25-27.

23. Derecho de cada uno de los miembros de la Dieta a vetar cualquiera de sus decisiones, lo que exigía que éstas fueran adoptadas por unanimidad.

24. A partir de 1573, la Rzeczpospolita se había convertido en una monarquía electiva. Cada rey electo debía suscribir las leyes fundamentales Ilamadas Artykuły Henrykowskie ("Artículos de Enrique"), que garantizaban el sistema constitucional del país, es decir, las normas que regulaban las relaciones entre el rey y la Dieta. El nuevo rey reconocía la monarquía electiva y se obligaba a decidir sobre la guerra y la paz en unión con el senado, no disponer del ejército sin el acuerdo de la Dieta, financiar parte del ejército y rodearse de un consejo de 16 senadores. Se establecía, además, que si el rey no cumplía con sus obligaciones para con la Rzeczpospolita, o atentaba contra los privilegios y leyes de la nobleza, los nobles estarían en su derecho de rescindir su obediencia al rey. Este último derecho fue usado como excusa por la nobleza y el clero para formar confederaciones. Una de las más conocidas e importantes en la historia de la Rzeczpospolita fue la de mayo de 1792, cuando una parte de la nobleza se reunió en la ciudad de Targowica, con la connivencia de Catalina II de Rusia, y rechazó la Constitución del 3 de mayo de 1791. Este hecho es considerado como la principal causa del segundo reparto de la Rzeczpospolita Obojga Narodów en 1792.

25. Veasé J. Kieniewicz, Historia de Polonia..., pp. 77-91. 
que terminó capitulando ante Rusia. En 1773 Rusia y Prusia firmaron un acuerdo para la realización de un segundo reparto. Rusia se anexionó entonces 250.000 $\mathrm{km}^{2}$ correspondientes a Ucrania y Bielorrusia, mientras que Prusia ocupó 57.000 $\mathrm{km}^{2}$. Tadeusz Włodek, un colaborador del gobierno pro-zarista, obtuvo de éste el 3 de agosto de 1793, la concesión de editar cualquier tipo de gaceta. A partir de 1794 sólo se publicó una revista en polaco, la Gazeta Krajowa ("La Gaceta Nacional"), órgano del régimen. Los polacos, bajo el general Tadeusz Kościuszko, organizaron la Insurrección de marzo de 1794 logrando importantes victorias. Sin embargo, en 1795 los imperios de Prusia, Austria y Rusia acuerdan el tercer y definitivo reparto del ya reducido territorio de Polonia ${ }^{26}$.

\section{El Kurier Polski del 1 de noviembre de 1755 al 28 de diciembre de 1757}

Como hemos indicado anteriormente, el Kurier Polski y las Uprzywilejowane wiadomości... fueron revistas editadas por los jesuitas que salían dos veces a la semana. Las dos formaban el único impreso de dos hojas de formato A-4 a doble columna. A mediados del siglo XVIII el número de noticias extranjeras en la parte del Kurier Polski aumenta, aunque suelen aparecer en la última hoja. La parte de las Uprzywilejowane wiadomości... sigue informando sobre países extranjeros. En este período la mayoría de las informaciones se copiaban de los periódicos suscritos por la redacción del Kurier Polski. Algunas revistas extranjeras, como las de París, se basaban en informaciones obtenidas por sus propias fuentes (empleando corresponsales), pero la mayoría reproducían las noticias publicadas por otras. Otra fuente de información, raramente insertada en el periódico, eran las relaciones de testigos, como los mercaderes, marineros u otras personas salvadas de las catástrofes. Independientemente de la fuente, todas las informaciones publicadas eran elegidas por el redactor, éste seleccionaba las que a su juicio eran más destacables y luego las traducía, añadiendo una nota con la fecha de publicación y la ciudad de procedencia ${ }^{27}$. Las noticias insertadas en el Kurier Polski o las Uprzywilejowane wiadomości... proceden sobre todo de París, Londres y Madrid; en ocasiones de Leipzig, Roma, Frankfurt, Constantinopla, Nápoles, Belem, Lisboa, Leiden, Cádiz, Amsterdam, Ginebra, Augsburgo, Hamburgo, La Haya, Utrecht, Praga, Viena, Bruselas, Venecia y Livorno, y raramente de Milán, Stuttgart, Berlín, Dublín, Ratisbona, Newcastle, Turín, Cleves, Oporto, Colonia, Tolón, Düsseldorf y Barcelona ${ }^{28}$.

Por lo que se refiere al terremoto de Lisboa del 1 de noviembre de 1755, las noticias proceden principalmente de los periódicos de París, Londres, Belem,

26. J. Łojek, Gazeta warszawska ..., pp. 17-27; J. Łojek, Prasa polska w latach 1661$1864 . . .$, pp. 27-45.; Vease J. Kieniewicz, Historia de Polonia..., pp. 86-95.

27. J.A. Drob, Obieg informacji w Europie XVII..., pp. 35-37.

28. Más frecuentemente: cada número o cada 2-3 números; menos frecuentemente: cada 4-6 números; raramente: 1 o 2 veces del 1 de noviembre de 1755 al 28 de diciembre de 1758 . 
Lisboa, Madrid y Cádiz, y en menor medida de Amsterdam, Leipzig, Milán, Roma, Utrecht, Hamburgo y Berlín. Una estimación aproximada del número de noticias publicadas sobre el terremoto de Lisboa, muestra que fueron relativamente escasas. El promedio de noticias dedicadas a otros países en las Uprzywilejowane wiadomości... es de unas doce, y en el Kurier Polski de tres. Es decir, aproximadamente 400 noticias en 6 meses en las dos partes del Kurier Polski. De ellas, sobre el terremoto de Lisboa tratan directa o indirectamente 32 artículos procedentes de diferentes ciudades (de los cuales seis son de la propia Lisboa, dos de Belem, dos de Cádiz y cinco de Madrid), publicados entre el 1 de noviembre y el 28 de diciembre de 1757; de éstos, 28 aparecieron entre el 1 de noviembre de 1755 y finales de marzo de 1756. Este número de artículos dedicados al terremoto no guarda mucha proporción con el trauma que esta catástrofe produjo en toda Europa. Pero hay que señalar que éste no fue el único terremoto o catástrofe natural que se menciona en las páginas del Kurier Polski y de otras muchas revistas europeas.

Durante el período que va del 1 de noviembre de 1755 al 29 de diciembre de 1756 en la prensa polaca se publicó 46 noticias de catástrofes, de las cuales 44 aparecen entre el 29 de noviembre de 1755 y finales de marzo de 1756. Según las informaciones del Kurier Polski, casi toda Europa occidental sufrió algunos temblores o terremotos. Entre el 29 de noviembre de 1755 y finales de marzo de 1756 se hace referencia a los que habían tenido lugar en Madrid, Salamanca, Segovia, Sanlúcar de Barrameda, Cartagena, Cádiz, Milán, Turín, Venecia, Padua, Verona, Anderlecht, Mastricht, Venlo, Arnhem, Nimega, Cleves, Neuvied, Neufs, Düsseldorf, Berlín, Juliers, Bonn, Colonia, Coblenza, Frankfurt, Lipstadt, Cassel, Magdeburgo, Duren, Stolberg, Szabo, Malmedi, Spa, Verviers, Balice, Neaux, Legie, Lille, Namour, París, Mons, Ath, Lovaina, Malies, Amsterdam, Utrecht, Amberes, Lider, Boskoop, Gornichem, Heusdem, Schedem, Woerdem, Lerrdam, Bregenopzoom, Dordrecht, Delft, Hoora, Spardam, Masek, Masmichk, Luttich, Achen. Aparecen también en las Islas Británicas (provincias del norte, Hertford, Londres, Newcastle) y en Norteamérica (Boston, New Hampshire). En las ciudades y regiones enumeradas, los temblores de tierra o los terremotos no causaron graves daños; se habla tan sólo de techos hundidos o de chimeneas derribadas. Cuando se encontraba cerca un río o el mar, casi siempre los movimientos sísmicos provocaban destrucción de barcos o inundaciones. Se dice que los peores efectos de los terremotos los sufrieron Ginebra y las ciudades cercanas, junto con Salé y Fez en el reino de Marruecos, donde murieron 600.000 personas $^{29}$. Los terremotos o temblores se producen una sola vez o en oleadas de varios: durante 1755 en los primeros días de diciembre y el 9 y luego del 24-27, y durante 1756 los días 26-27 de enero, 1820 de febrero y, el último, el 14 de marzo.

29. Kurier Polski y Uprzywilejowane wiadomości z cudzych krajów, no CXXXV, París-24 I 1756, nํㅡㄴ CXXV 1755-CXLI 1756. 
Otras calamidades descritas en este período son los desbordamientos de los ríos franceses (Ródano, Loira, Saona), tempestades en el Mediterráneo, inundaciones en Venecia, Iluvias en Madrid y Francfort e intensas heladas en Praga. Se informa sistemáticamente de las ondas sísmicas producidas por el Vesubio. Entre las calamidades más curiosas están la epizootia de Baviera, el hundimiento de una parte de la isla de Madeira y de otras islas pequeñas a su alrededor, la aparición de nuevas rocas en los alrededores de las Canarias y de Cádiz, un extraño olor que provocó mareos a los pescadores de Lubecka y Gluckstadt, un "espectáculo azul" en Estocolmo, cuando un objeto parecido a la luna que proyectaba chispas tras de sí atravesó el cielo el día 16 de diciembre, y el incendio de Constantinopla ${ }^{30}$.

En conjunto, de las aproximadamente 400 noticias extranjeras entre noviembre de 1755 y marzo de 1756 sólo 28 tratan del terremoto de Lisboa y 44 de otras calamidades o catástrofes.

\section{El terremoto en Lisboa visto por el lector del Kurier Polski}

En los meses de octubre y noviembre de 1755, el lector polaco no leyó ninguna noticia referente a calamidades naturales. La primera en aparecer en el Kurier Polski fue el día 10 de diciembre, consistiendo en un artículo reproducido de la revista de Versalles, con fecha del 20 de noviembre, en el que se relata como un mensajero llegó a la Corte francesa informando sobre el terremoto de Lisboa y Cádiz del día 1 de noviembre. El mensajero informó sobre la gran destrucción de la ciudad, la muerte de alrededor de 50.000 personas, el incendio que se extendió por la ciudad, y el grave desbordamiento del Tajo. También describe la situación de la familia real y se refiere la muerte del embajador español, Bernardo Antonio de Boxadors y Sureda, conde de Perelada ${ }^{31}$ :

“El conde de Peralda [Peralada], diputado español, pereció bajo el pórtico de su palacio, junto con nueve miembros de se servicio; sin embargo, el Conde de Baschi d'Aubigne, diputado francés, fue muy afortunado, porque con su esposa y toda su familia quedó con vida escapando de la ciudad al campo. Para el rey, la reina y toda la familia real, fue muy afortuno que no estuvieran en Lisboa pero en Belem, donde también se produjeron temblores, aunque no tan vehementes" ${ }^{\prime \prime 2}$.

30. Kurier Polski, nº CXXXII ... ; Uprzywilejowane wiadomości, no CXXXII, Nápoles-23 XII.

31. Sobre el conde de Perelada véase TARACHA C., "El marques de la Ensenada y los servicios secretos españoles en la época de Fernando VI", Brocar, 25 (2001), pp. 109-122 y D. OZANAM, Les diplomates espagnols du XVIIle siècle. Introduction et repértoire biographique (1700-1808), Madrid-Bordeaux, 1998, pp. 197-198.

32. Kurier Polski, no CXXV, Versalles-20 XI. 
En el número siguiente de la revista, se publicó la relación de Madrid. En ella destacó la actitud del diputado francés, quien salvó al único hijo del embajador español fallecido y le convidó junto con el servicio del conde de Perelada a su mansión de campo ${ }^{33}$.

Después de esta noticia, las siguientes llegan con frecuencia añadiendo otros detalles, a veces contradictorios, como en el caso del número de muertos.

\section{Duración del terremoto}

Según las noticias de la prensa polaca, la tragedia presentó sus síntomas al atardecer del día 31 de octubre cuando la niebla era de color rojizo. Al amanecer del día siguiente hubo un fuerte viento y algunos temblores; pero la verdadera tragedia llegó a las 10 de la mañana y duró de 2 a 5 minutos (dependiendo de las fuentes de la noticia). Por la tarde, de las grietas que se abrieron en la tierra se originó un incendio que durante 48 horas seguidas devastó por completo el principal barrio de Lisboa. Unas horas más tarde, las aguas del Atlántico atravesaron las murallas y entraron en la ciudad causando más daños. El terremoto del primer día se prolongó durante diez horas, con diversas pausas, pero los temblores se repitieron casi incesantemente en los días siguientes, hasta los nuevos terremotos de los días 8 y 18 de noviembre (algunos artículos informan de terremotos constantes entre el 1 y el 16 de noviembre). La nueva oleada se produjo los días 3, 11 y 21 de diciembre, cuando el terremoto duró 3 minutos. Aunque las destrucciones del primer día fueron las más graves, los posteriores temblores sísmicos ocasionaron la destrucción de andamios y reconstrucciones provisionales ${ }^{34}$.

En enero se produjeron también una serie de temblores lo bastante fuertes como para destruir el palacio del Almirante Mayor de Portugal y otros edificios que se habían mantenido en pie hasta ese momento ${ }^{35}$. Durante los días 16-19 de febrero igualmente se sigue informando de temblores, aunque menos graves, que de nuevo retrasan las obras de reconstrucción, y algunos el 1 de marzo y los días 1 y 27 de abril ${ }^{36}$.

\section{El rey y la familia real}

De acuerdo con las reglas de la época, la mayor parte de las noticias estaban dedicadas a la situación de la familia real. Kurier polski e Uprzywilejowane wiadomości..., publicaban, sin embargo, muchas noticias del mundo doméstico de

33. Uprzywilejowane wiadomości, no CXXVI, Madrid - 11 XI.

34. Kurier Polski, $\mathrm{n}^{\circ} \mathrm{CXXV}$, Versalles-20 XI; Uprzywilejowane wiadomości, $\mathrm{n}^{\circ} \mathrm{CXXXX}$, Hamburgo-23 XII, no CXXXI, Belem-12 XII, París-26 XII; Kurier Polski, no CXXXII, Madrid-26 XII.

35. Uprzywilejowane Wiadomości, no CXXXIX, Lisboa- $20 \mathrm{I}$.

36. Uprzywilejowane Wiadomości, no CXLII, Belem-19 II, Madrid- 1 III; Kurier Polski, $\mathrm{n}^{\text {o }}$ CXLIV, Lisboa- 2 III, nº CXLVI, Lisboa - 7 IV, nº CLII, Leiden-1 VI. 
los caballeros, ofreciendo en conjunto una imaginen más variada. Sólo cuando se centra en las noticias extranjeras reimpresas se tiene la perspectiva de la Europa occidental según las cuales, por ejemplo, el rey de Portugal permaneció durante 24 horas sin servicio y sin comida pero a salvo, milagrosamente, de la catástrofe que destruyó la ciudad. José I, la familia real, la corte, y muchos de los ciudadanos supervivientes, se refugiaron en el campo, a media milla de Belem, y allí pasaron juntos los peores momentos de la tragedia. La mayoría de la población, hasta 200.000 personas, escapó de la ciudad sin tiempo para llevarse las cosas más necesarias; por consiguiente se encontraron vestidos ligeramente en medio del campo sin comida ni ropa de abrigo. Después de pasar cuatro días en este miserable estado, la familia real decidió instalarse en su palacio de Belem, que se había salvado de la destrucción ${ }^{37}$. De acuerdo con otras informaciones, hasta mediados de enero o febrero (según las diferentes fuentes), el rey y su familia permanecieron en tiendas de campaña en el campo, en las afueras de la ciudad, y en los meses mencionados se trasladaron a su residencia de Salvaterro ${ }^{38}$. Otros artículos relatan cómo el rey rechazó trasladarse a la ciudad de Oporto y que hasta febrero de 1756 vivió en una tienda de campaña cerca de Lisboa para velar por la capital ${ }^{39}$.

\section{La ayuda}

Según el conocimiento del lector polaco, unos diez días después el terremoto, el rey de España, Fernando VI, a la sazón cuñado por partida doble del monarca lusitano, conmovido por la miserable suerte de los súbditos portugueses, le ofreció dinero (40.000 "pistolas", es decir, 80.000 escudos) y el envío de víveres a la capital. Posteriormente, el monarca español otorgó el título de chambelán (gentilhombre de cámara) a Fernando Felipe Boxadors y Sureda, hijo superviviente del embajador español ${ }^{40}$. Por falta de informaciones de Lisboa y por desconocimiento de la situación en que se hallaba, Madrid envió al conde de Aranda como embajador extraordinario a la capital de Portugal y cin-

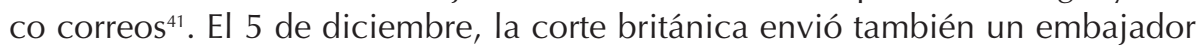
con cartas de condolencia y 5.000 libras esterlinas en metálico, ofreció 6.000 en provisiones y se comprometió a dotar más recursos que saldrían de Londres y de puertos irlandeses ${ }^{42}$. José I aceptó los materiales de construcción y los víveres ofrecidos por Inglaterra y España, pero rechazó la ayuda monetaria ${ }^{43}$. Los

37. Kurier Polski, $\mathrm{n}^{\circ} \mathrm{CXXV}$, Versalles-20 XI.

38. Uprzywilejowane wiadomości, nº CXXXIX, Lisboa-20 I, nº CXLII, Belem-19 II.

39. Uprzywilejowane wiadomości, no CXXXV, Lipsk-7 II 1756.

40. Kurier Polski, no CXXV, Versalles-20 XI; Uprzywilejowane wiadomości, no CXXV, Madrid-11 XI.

41. Uprzywilejowane wiadomości, $\mathrm{n}^{\circ} \mathrm{CXXVII}$, Madrid-11 XI.

42. Uprzywilejowane wiadomości, $\mathrm{n}^{\circ}$ CXXVIII, Londres-2 XII, $\mathrm{n}^{\circ}$ CXXXII Londres-30 XII.

43. Uprzywilejowane wiadomości, no CXXXVII, Lisboa-6 I. 
ciudadanos lisbonetas obtuvieron ayuda de su propio rey, quien les permitió cavar en las ruinas y remover la tierra en busca de sus propiedades, entre ellas los diamantes de la Casa real. Además, el monarca ofreció a sus súbditos cualquier otro tipo de ayuda que pudiesen necesitar ${ }^{44}$.

\section{Destrucción de la ciudad por el terremoto y otras calamidades}

Lisboa, según las informaciones publicadas en la prensa polaca, quedó destruida en uno o dos tercios por el terremoto, los incendios y el desbordamiento del Tajo. La destrucción principal se debió al terremoto del 1 de noviembre, aunque no toda la ciudad quedó en ruinas ${ }^{45}$. Las demás devastaciones fueron consecuencia del maremoto, los incendios y los temblores y terremotos que se produjeron en los días posteriores. Las enormes olas del Atlántico devastaron los edificios en la zona costera, arrastrando las mercancías de las tiendas y almacenes y arrancando los barcos anclados en el mar. Los ríos Tajo, Miño, Duero y Guadiana se desbordaron causando muchos daños en Lisboa y en otras zonas del país. Varias sierras del reino de Portugal y del Algarve, como las de la Estrella, Marvan, Sintra, Arabia y Monte Suono vieron alterada su fisonomía; unas partes se desplomaron mientras que otras se elevaron, causando destrozos en los valles ${ }^{46}$.

Conforme a las noticias, el terremoto y sus consecuencias afectaron no sólo a la ciudad de Lisboa, sino también a Villa Nova de Paiva, Tavira, Castro Marim, Beja, Elvas, Portalegre, Setúbal, Cascais, Sintra, Santarem, Coimbra, Castelo Branco, Lamego, Guimaraes, Villa Real, Braganza y Pinhel. Según la revista polaca, entre los daños más graves sufridos por la economía del reino, estaban los producidos en las salinas y el puerto de Setúbal. Entre las otras devastaciones padecidas hay que incluir también los robos. Pasado el período de miedo y el trauma, los relatos nos informan de multitud de casos de pillaje y latrocinio. La ocasión hace al ladrón, y una ciudad inmersa en el caos era una oportunidad para robar todo lo que se podía de las ruinas y de las viviendas, almacenes, tiendas y bancos abandonados en su huida por los propietarios. Entre los muertos hubo muchos a los que les faltaban los dedos de las manos, amputados sin duda para quitarles los anillos más fácil y rápidamente. El robo era tan provechoso que los ladrones prendían fuego a los restos de edificios e iglesias para desanimar a los que regresaban ${ }^{47}$.

Una de las primeras decisiones del gobierno fue el unir esfuerzos para detener los continuos robos. A pesar del gran número de delitos cometidos, entre los

44. Uprzywilejowane wiadomości, n⿳⺈ CXXXVIII, Belem-16 I.

45. Kurier Polski, $\mathrm{n}^{\circ} \mathrm{CXXV}$, Versalles-20 XI.

46. Uprzywilejowane wiadomości, $\mathrm{n}^{\circ} \mathrm{CXXVI}$, Madrid-11 XI.

47. Kurier Polski, no CXXXIV, Londres-16 I 1756; Uprzywilejowane wiadomości, no CXXXIV, París-12 I 1756. 
incendiarios y ladrones detenidos no se menciona ningún portugués, sólo prisioneros y esclavos huidos, desertores españoles y franceses que habían encontrado refugio trabajando en la marina mercante, y un negro:

"Los presos y esclavos, en estas horrorosas circunstancias, buscaron modos para escapar consiguiendo ésto, se pusieron a robar. Por desgracia, bastantes desertores españoles y franceses, junto con grumetes ingleses, se les adhirieron. (...) Un negro, cuando le tocó, confesó, que después del primer temblor, prendió fuego en siete sitios de la ciudad"48.

De los edificios representativos de la administración del país, como la Catedral, el Palacio Real, el Archivo y el Tesoro, sólo quedó en pie la Casa de la Moneda. Se convirtieron en ruinas algunas iglesias que habían sido costeadas en gran parte por los ciudadanos y el reino, como la Catedral ${ }^{49}$. Entre los edificios destruidos más destacables se menciona el palacio del Almirante Mayor de Portugal y las villas de los embajadores de España y Francia ${ }^{50}$.

La actividad de la ciudad sufrió restricciones por la destrucción de infraestructuras económicas como la residencia de Compañía de las Indias, los almacenes situados en las cercanías del puerto, las grandes arterias de comunicación (como la que iba del Palacio Real a la Aduana) y la mayor parte de los bancos. Entre los más perjudicados estaban los hombres de negocios ingleses y la Compañía de las Indias, que tenían sus almacenes situados en el litoral de Lisboa:

"la viuda de un comerciante, después de la noticia de la ruina de la ciudad, perdió 10.000 libras esterlinas que quería recibir para su arreglo, se emocionó tanto con la noticia, que murió en dos días" ${ }^{\prime \prime 1}$.

Como consecuencia de la destrucción del puerto, todo el comercio marítimo quedó interrumpido, incluido el abastecimiento de la ciudad. Unos 30 hombres de negocios de Lisboa quebraron. Las pérdidas en las primeras dos semanas se elevaron a 20.000 libras esterlinas. Entre un $20 \%$ y un $30 \%$ de esta suma correspondía a pérdidas ocasionadas por robos e incendios provocados por los ladrones ${ }^{52}$. La destrucción de los inmuebles sumaba alrededor de 50.000 cruzados $^{53}$.

48. Kurier Polski, no CXXXX, Lisboa-17 XI; otros en no CXXIX, Lipsk-27 XII Roma-20 XII; Uprzywilejowane wiadomości, no $\mathrm{CXXXI}$, Belem-12 XII.

49. Kurier Polski, no CXXXII, Madrid-23 XII.

50. Kurier Polski, no. CXXV, Versalles-20 XI, nº CXXVI, Madrid-11XI, noXXVIII Cádiz-7 XII; Kurier Polski, no. XXXX, Lisboa-17 XI, Roma-20 XII; Uprzywilejowane wiadomości, nº CXXXIX, Lisboa-20 I.

51. Uprzywilejowane wiadomości, no CXXX, París-19 XII.

52. Kurier Polski, no. XXXX, Lisboa-17 XI.

53. Kurier Polski, no CXXXVII, Belem-13 I. 


\section{Los fallecidos}

Las cifras sobre el número de muertos fueron muy variadas. Según la primera noticia, cuando todavía quedaban cadáveres sepultados bajo las ruinas de la ciudad, las cifras barajadas eran de 50.000 muertos. Las noticias aparecidas más tarde hablaban de entre 6.000 y 100.000 muertos $^{54}$. En una noticia fechada en Lisboa el día 17 de noviembre, se dice que no hubo tantos muertos como se suponía al principio. Entre la nobleza portuguesa se dieron cinco casos: el marqués de Louriçal; el conde de Lumeres y su hija, la señora Anna de Mososo; X. Francisco de Noronba; uno de los canónigos de la Catedral; y Fray Márquez d’Angeia. Además perdieron también la vida 50 monjas y otras 70 personas del Convento de Santa Clara que en el momento del terremoto estaban en el coro, y 3 jesuitas $^{55}$. A mediados de enero, las estimaciones sobre el número de muertos oscilaban entre 25.000 y 30.000 , aunque no eran definitivas ${ }^{56}$.

\section{La causa}

En un principio se dijo que había sido un castigo del cielo motivado por los pecados de sus habitantes ${ }^{57}$. El escarmiento divino había sido tan grande que había sometido a Lisboa a toda clase de calamidades, unas naturales y otras causada por su población. Esto se veía en la sucesión de innumerables terremotos, inundaciones e incendios, que estallaban cada vez que se reconstruía una parte de la $\operatorname{ciudad}^{58}$. Y dentro del ámbito científico se alertaba sobre como el terremoto causaría un cambio climático, con el efecto de inviernos más suaves pero muy lluviosos ${ }^{59}$. Durante los primeros días de enero de 1756, en tres iglesias de Roma se dieron gracias a Dios por los supervivientes y se imploraba la ayuda divina para los que todavía estaban recuperándose de la tragedia ${ }^{60}$.

\section{Obras y restauración}

A mediados de enero, las redes de comercio internacional empezaron a funcionar. Se comenzó a trazar el plano arquitectónico de reconstrucción de la capital, que exigió consultas con ingenieros de Inglaterra y Francia. El proyecto contemplado no consistía simplemente en la restauración de la ciudad, sino en su reconstrucción sobre un estilo moderno y funcional:

54. Kurier Polski, no. CXXV, Varsalles - 20 XI; no XXXX, Roma-20 XII; Uprzywilejowane wiadomości, no. CXXVII, París-1 XII.

55. Kurier Polski no CXXVI, Madrid-11 XI; $\mathrm{n}^{\circ} \mathrm{XXXX}$, Lisboa-17 XI, Roma-20 XII.

56. Kurier Polski, no CXXXVII, Belem- 13 I.

57. Kurier Polski, no XXVIII, relación de París-3 XII y de Ámsterdam-14 XII.

58. Uprzywilejowane wiadomości, no CXXXIV, París-12 I 1756.

59. Uprzywilejowane wiadomości, $\mathrm{n}^{\circ} \mathrm{XXXX}$, París-17 XII.

60. Uprzywilejowane wiadomości, no CXXXIII, Roma-3 I 1756. 
"La nueva Lisboa, por la regularidad de sus calles y posición de sus sitos públicos, será más bella y magnífica. Todo lo necesario para éste lograr este objetivo, está preparándose en las provincias, los albañiles se están alistando de países extranjeros, se planea emplear alrededor de 100.000 pobres, con sueldos muy altos" ${ }^{\prime 61}$.

La nueva capital sería más bella y funcional, con anchas avenidas de trazados regulares y grandes plazas públicas. El plano arquitectónico aprobado por el rey suponía una ciudad más grande, con edificaciones de hasta dos plantas. Con este objetivo se planeó emplear a 100.000 personas de clase humilde en las obras públicas. Para reconstruir el Palacio Real se decidió contratar a 3.000 especialistas de Inglaterra, brigadas de carpinteros y albañiles que debían reconstruir el palacio en el plazo de cinco años.

Una decisión que provocó muchas dudas fue la prohibición de las obras de reconstrucción en la capital hasta que el plano arquitectónico de la nueva ciudad estuviese listo y se hubieran quitado los escombros y examinado la firmeza del terreno ${ }^{62}$. Los supervivientes volvieron entonces a la ciudad para buscar y recuperar los restos de sus bienes ${ }^{63}$. Ante todo había que protegerse de las epidemias y para ello se organizó la quema de cadáveres ${ }^{64}$.

La mano de obra y los materiales de construcción procedían del propio Portugal, de Inglaterra y España, mientras que el dinero era sólo portugués, ya que, recordemos, desde el principio José I rechazó la ayuda monetaria de esos reinos. En marzo, a instancias de la reina Mariana Victoria, el monarca terminó aceptando 46.000 "pistolas" (92.000 escudos) del monarca español. El rey portugués hizo también las gestiones pertinentes para obtener un préstamo del Banco de Venecia. Por eso hubo que reducir los gastos públicos al mínimo y dedicar todos los recursos a restablecer el orden y el funcionamiento de la capital. José I retuvo el dinero asignado al sostenimiento de instituciones públicas como el teatro y la ópera y el pago de sueldos a los actores. Además, subieron los precios de los artículos importados ${ }^{65}$.

Uprzywilejowane wiadomości... no dice nada sobre la reconstrucción del palio y de la sede del nuncio en Portugal por el rey, pero se menciona la decisión del Papa de poner mil escudos de renta anual a disposición de las autoridades eclesiásticas de Lisboa ${ }^{66}$.

61. Uprzywilejowane wiadomości, no CXXXVII, Lisboa-6 I.

62. Kurier Polski, no CXXXVI, Hamburgo-11 II, no CXXXVII, Belem-13 I, nํㅡㄴ CLIV, Lisboa-2 III; Uprzywilejowane wiadomości, no CXXXVII, Lisboa-6 I, no CXXXIX, Lisboa-20 I, no CXL, Belem-30 I.

63. Kurier Polski, no CXXV, Versalles-20 XI.

64. Uprzywilejowane wiadomości, no CLVI, Lisboa-16 III.

65. Uprzywilejowane wiadomości, no CXL, Belem-30 I, no CXLI, Lisboa-3 II, no CLII, Belem-19 II, no CLIV, Lisboa-2 III; Kurier Warszawski, noㅡ CLIII, Lisboa-24 II.

66. Uprzywilejowane wiadomości, no CLIV, Roma-20 III. 


\section{El terremoto de Lisboa visto por países}

Los temas presentados en la prensa polaca mostraban un cierto perfil político. No se publicaba ninguna información que pudiera irritar a los más poderosos: algunos nobles, la Corte o las autoridades eclesiásticas. La prensa tampoco funcionaba como foro de discusión política ni como órgano político de un partido. Este comportamiento editorial estaba acorde con el periodismo europeo, según se concebía el objetivo de la prensa: informar al público sobre los hechos sin añadir comentarios y juicios personales del periodista ${ }^{67}$. Esta manera de concebir el periodismo pronto desaparecería a finales del siglo XVIII. En realidad, el gobierno podía en cualquier momento anular el privilegio editorial y en consecuencia cerrar la redacción. Asimismo, algunos nobles tenían poder suficiente para influir en las decisiones del monarca. En la práctica, esto significó que la prensa se convirtió en el órgano del rey y del gobierno y se mantuvo siempre "políticamente correcta". Por eso no se reprodujo ninguna de las múltiples opiniones que se tenían sobre el marqués de Pombal. Hechos como la actuación contra los jesuitas, la abolición de la esclavitud en Portugal, la modernización del ejército, las reformas centralistas tales como la educación, economía, comercio y el uso de la propaganda estatal, a pesar de que estaban en la directa relación con los hechos publicados en Kurier Polski, no quedaron mencionados en la prensa polaca ${ }^{68}$. Tampoco se publicaron opiniones sobre las decisiones adoptadas por el rey deteniendo la reconstrucción ${ }^{69}$. La falta de crítica de las reformas absolutistas introducidas por Pombal en un país donde la libertad de la nobleza fue uno de los pilares del funcionamiento de la Rzeczpospolita, donde el despotismo absoluto estaba considerado como el enemigo principal de dicha libertad, podía causar dudas. Si tenemos en cuenta qué artículos de la Europa occidental principalmente referidos al régimen del despotismo absoluto aparecieron traducidos en el Kurier Polski según la manera editorial de la época, sin comentarios, la cuestión nos queda más entendible. En las fuentes analizadas hay claras evidencias de esta política, especialmente en el caso de los países o grupos sociales con mayores intereses en sus relaciones con Portugal ${ }^{70}$. Los temas principales abordaban problemas que indicaban los respectivos intereses que cada uno tenía en relación con Portugal.

En las noticias procedentes de Inglaterra y España, dos países cercanos a Portugal y a la vez competidores, el peso se ponía en la actitud de sus reyes frente

67. J. Łojek, Prasa Polska w latach 1661-1864, Varsovia, 1976, pp. 19-20; Dziennikarze $i$ prasa warszawska w XVIII wieku (Periodismo y presa varsoviana en el siglo XVIII), Varsovia, 1960, p. 26.

68. K. Maxwell, Pombal, paradox of Enlightenment, Cambridge, 1995, pp. 16-35, 87-109.

69. J. F. Saraiva, Krótka historia Portugalii, Cracovia, 2000, pp. 253-266; A. H. de Oliveira Marqués, Historia Portugalii, Varsovia, 1987, t.2, s.37-38; J. A. Drob, Obieg informacji w Europie w XVII wieku, Lublin, 1993, pp. 73-74, 97.

70. K. Maxwell, Pombal..., pp. 16, 37-68. 
a la tragedia del reino de José I. Ambos países ofrecen aparentemente su ayuda como un acto humanitario y compasivo, omitiendo el aspecto de las obligaciones políticas y económicas que contraería Portugal en caso de aceptar la ofer$\mathrm{ta}^{71}$. Otro lugar del que procede un número de informaciones suficiente para valorar su perfil político es Roma, preocupada más por asuntos eclesiásticos tales como el grado de destrucción de conventos e iglesias, el número de religiosos fallecidos, la financiación del nuevo palio para el nuncio en Portugal o la nueva renta para reestablecer la estructura eclesiástica ${ }^{72}$.

Las noticias reproducidas de los periódicos de Lisboa o Belem suelen destacar la persona del rey José I como alguien que está constantemente al lado de sus súbditos, no abandonándoles en los meses posteriores a la tragedia, sufriendo con ellos, viviendo en una tienda de campaña y sintiéndose feliz cuando empieza a restablecerse la vida en Lisboa $^{73}$. Es el ideario del despotismo ilustrado, en el cual la figura del rey constituye la parte especial de la propaganda estatal. El monarca es considerado como el buen ilustrado y padre de sus súbditos. Por esta razón las revistas no publican que si José I durmió en una tienda de campaña, fue por miedo a que se le cayese todo encima, o sus posteriores ataques de claustrofobia. Existen también relatos o cartas de marineros que tratan sobre asuntos económicos y describen la situación en los puertos de Lisboa o Setúbal ${ }^{74}$.

La actitud editorial de no opinar sobre los hechos no significa que el público careciera de sus propias opiniones; simplemente la revista no era foro para ello. Esto nos lleva a la conclusión de que al lector, igual que al redactor (responsable de elegir las informaciones), les interesaba más la noticia en sí misma que los datos concretos y el análisis de los mismos. Por eso el lector se quedó sin conocer exactamente el número de muertos en Lisboa, auque se prometió su publicación. No se dijo nada de los funerales, aparte de las precauciones tomadas para evitar epidemias; de la situación de los lisbonetas sin techo, comida, agua o vestido; de los detalles y discusiones sobre el proyecto de reconstrucción, ni de la aceptación o rechazo de la ayuda ofrecida por otros países. Tampoco había nada sobre el marqués de Pombal, hombre que provocó tanta discusión en Portugal ${ }^{75}$.

71. Uprzywilejowane wiadomości, no CXXVI, Madrid-11 XI, no CXXVII, Madrid-11 XI, $\mathrm{n}^{\circ}$ CXXVIII, Londres-5 XII, no CXXXII, Londres-30 XII; Kurier Polski, no CXXVIII, Madrid-25 XI, noㅡ. CXXXII, Londres-9 I, Madrid-23 XII, no CXXXIV, Londres-16 I.

72. Kurier Polski, no CXXX, Roma-20 XII; Uprzywilejowane wiadomości, no CXXXIII, Roma-3 I, no CXXXVII, Roma-1 II, no CXXXVIII, Roma-7 II, $\mathrm{n}^{\circ}$ CXLI, Roma-28 II, $\mathrm{n}^{\circ}$ CXLIV, Roma-20 III.

73. Kurier Polski, no CXXX, Lisboa-17 XI, no CXXXVII, Belem-13 I, no CXLIII, Lisboa-24 II, no CXLIV, Lisboa-2 III, nº CLXXIX, Lisboa-2 XI; Uprzywilejowane wiadomości, no CXXXI,

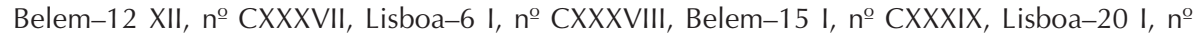
CXL, Belem-30 I, nํ CXLI, Lisboa-3 II, nº CXLII, Belem-19 II, nํ CXLVI, Lisboa-16 III, nº CXLIX, Lisboa-7 IV.

74. Kurier Polski, nº XXVIII, Amsterdam-14 XII, nº CXXIX, Leipzig-27 XII.

75. Vease K. Maxwell, Pombal..., passim. 
Por el contrario, se incluyeron muchas noticias sobre la situación de las clases acomodadas, sobre todo de la familia real, y también sobre curiosidades naturales. Portugal estaba al otro lado de Europa, y su gran distancia la colocaba en los fines de la civilización europea. Los acontecimientos que allí tenían lugar no afectaban directamente a la mayoría de los lectores, desconocedores del mundo portugués. Por eso se publicaron noticias referentes a la familia real y a otros poderosos en cuanto a su actitud frente a sus súbditos, o bien a las relaciones entre monarcas, que era una información no tanto sobre Lisboa sino sobre el mundo internacional de los potentados, conocido por los lectores de todos los países y que éstos deseaban imitar.

Por la misma razón se acentuaron tanto los detalles sobre las alteraciones naturales provocadas por el terremoto y sus consecuencias para el hombre. A nuestro parecer no les interesaba tanto la destrucción del puerto y de la ciudad de Lisboa como el desencadenamiento de los elementos, incontrolados por el hombre. Otra confirmación de estos resultados la proporciona la consideración de la fecha de aparición de las noticias sobre terremotos. El auge se produce inmediatamente después de la primera noticia del 10 de diciembre de 1755 y dura hasta fines de marzo de 1756. El 7 de mayo y el 22 de diciembre de 1756 se incluyó una noticia sobre otro terremoto en Lisboa y otra conmemorando la tragedia del 1 de noviembre. Durante todo el año de 1757 no apareció ninguna mención en la prensa polaca sobre la situación en Lisboa. Prácticamente desde abril de 1756 el principal interés de la prensa se traslada de repente de los cataclismos naturales al tema esencial para la Rzeczpospolita -la tensa situación internacional existente entre Inglaterra y Francia, que pronto se convertiría en la Guerra de los Siete Años ${ }^{76}$.

La redacción del Kurier Polski, teniendo en cuenta las expectativas de sus clientes, presentaba los temas con más demanda, los tópicos adecuados al gusto de los lectores con el objetivo de atraerlos a la compra de su revista. Por estas razones, el terremoto en Lisboa fue presentado con el mismo interés que se ponía en las noticias sensacionalistas o los sucesos criminales, equivalentes hoy día a las noticias sobre ovnis u otros fenómenos extraordinarios.

76. J. Kieniewicz, Historia de Polonia..., pp. 81-82; K. Maxwell, Pombal..., p. 115. 